\title{
The effectiveness of different approaches for in situ measurements of organic carbon using VNIR in Poyang basin
}

\author{
Meihua Yang ${ }^{1}$, Hongyi $\mathrm{Li}^{2}$, and Shi Zhou ${ }^{3}$ \\ ${ }^{1}$ Yuzhang Normal University \\ ${ }^{2}$ JiangXi University of Finance and Economics \\ ${ }^{3}$ Zhejiang University
}

June 13, 2020

\begin{abstract}
In situ visible near infrared diffuse reflectance spectroscopy (VNIR) is a rapid and in-situ sensing approach and can provide analytical dense soil data reflecting multiple physical and chemical properties of soil. A total of 246 in situ soil samples were collected and scanned in 2016-2018. The dataset from 2016-2017 was used as the calibration dataset to develop the dry ground model and to develop to the in situ correction matrix using the dry and in situ spectra. The dataset from 2018 was used as the validation dataset using the in situ spectra. Four in situ correction methods, external parameter orthogonalization (EPO), direct standardization (DS), piecewise direct standardization (PDS), and generalized least squares weighting (GLSW) were used to remove the in situ effect on the spectra. In addition, two models, partial least squares regression (PLSR) and support vector machine (SVM), were used to detect the effectiveness of the prediction. The results showed that the four in situ corrections could remove the error introduced by in situ measurement to some extent. The four in situ corrections, when combined with SVM, could better reduce the errors caused by in situ measurements than the same corrections combined with PLSR. EPO correction outperformed the other three methods, and EPO-SVM obtained the best prediction with the lowest RMSE (1.91 g $\mathrm{kg}-1$ ) and highest Lin's concordance correlation coefficient (LCCC) (0.84). We conclude that the EPO-SVM methods using in situ spectra can detect soil organic carbon in the Poyang Lake area in a rapid and minimally invasive manner.
\end{abstract}

\section{Hosted file}

The effectiveness of different approaches for in situ measurements of organic carbon using VNIR in Poya available at https://authorea.com/users/333231/articles/459453-the-effectiveness-ofdifferent-approaches-for-in-situ-measurements-of-organic-carbon-using-vnir-in-poyangbasin

\section{Hosted file}

Table.docx available at https://authorea.com/users/333231/articles/459453-the-effectivenessof-different-approaches-for-in-situ-measurements-of-organic-carbon-using-vnir-in-poyangbasin

\section{Hosted file}

Figure.docx available at https://authorea.com/users/333231/articles/459453-the-effectivenessof-different-approaches-for-in-situ-measurements-of-organic-carbon-using-vnir-in-poyangbasin 